\title{
RESEARCH
}

\section{National and provincial retention of medical graduates of Memorial University of Newfoundland}

\author{
Maria Mathews, James T.B. Rourke, Amanda Park
}

$\infty \quad$ See related article page 37I

\section{ABSTRACT}

Background: Memorial University of Newfoundland (MUN) established its medical school in 1967 to meet the growing demand for physicians and alleviate the reliance on other Canadian and international medical schools for physicians. However, it is unclear how many of the graduates remained to practise in Canada and in Newfoundland and Labrador (NL). We conducted this study to identify the characteristics and predictors of MUN medical graduates working in Cana$\mathrm{da}$ and $\mathrm{NL}$ after residency training.

Methods: We linked data from class lists, and alumni and postgraduate databases with data from the Southam Medical Database to determine 2004 practice locations for MUN graduates from 1973 to 1998 . Multiple logistic regression analysis was used to identify predictors for working in Canada and in NL.

Results: Of the 1322 MUN graduates in our study, 1147 (86.8\%) were working in Canada and 406 (30.7\%) in NL in 2004. Predictors of physicians working in Canada included female sex (odds ratio [OR] 1.44, 95\% confidence interval [Cl] 1.01-2.04), being from Canada (OR 3.71, 95\% Cl 1.15-2.21), graduating in the $1980 \mathrm{os}(\mathrm{OR} 1.52,95 \% \mathrm{Cl} 1.02-2.24$ ) and 1990 (OR 2.01, 95\% Cl 1.31-3.09) and having done some or all residency training at MUN (OR 1.59, 95\% Cl 1.53-9.01). Predictors of physicians working in $\mathrm{NL}$ included having a rural background (OR 1.37, 95\% Cl 1.04-1.81), being from NL (OR 9.23, 95\% Cl 5.52-15.44) and having done some or all residency training at MUN (OR 5.28, 95\% Cl 3.80-7.34).

Interpretation: The MUN medical school has made a substantial contribution to the local physician supply, producing over half the physicians working in the province in 2004. Initiatives to increase national and provincial retention of medical graduates include attracting rural students to medical careers, increasing admission of local students and providing incentives for graduates to complete their residency training in the province.

CMAJ 2006;175(4):357-60

7 he "brain drain" or departure of physicians from Canada to other countries or from one province to another is believed to contribute to national and regional physician shortages. Between 1975 and 1999 the absolute number of physicians emigrating from Canada varied consid- erably, from a low of 242 in 1975 to a high of 777 in $1994 .{ }^{1}$ In 2004 the number of physicians returning to Canada exceeded the number leaving the country. ${ }^{2}$ Within Canada, between 2000 and 2004 Newfoundland and Labrador (NL), Quebec, Manitoba and Saskatchewan had consistent net losses in physician supply owing to interprovincial migration, whereas Ontario, Alberta and British Columbia had consistent net gains. ${ }^{3}$ During these years, the net loss of physicians from NL ranged from 28 physicians in 2004 to 50 physicians in 2000.

In their longitudinal study of the Class of 1989 , Ryten and colleagues $^{4}$ reported substantial variation in the average provincial retention rate of Canadian medical schools; that is, the proportion of graduates living in the province at the time of admission to medical school who were still residing there once their training was complete. The national average was $43.4 \%$, and by province it ranged from $\mathrm{I} 4.2 \%$ (Prince Edward Island) to $78.6 \%$ (Ontario), which reflected a gradient from small rural provinces to larger, more urban provinces. Although previous studies have noted high levels of interprovincial migration of physicians, we were unable to find any study that identified the factors associated with graduates of medical schools leaving or staying in the province of their medical training.

The medical school of Memorial University of Newfoundland (MUN) was established in 1967 to meet the growing demand for physicians and alleviate the reliance on other Canadian and international medical schools for physicians. By 2004 MUN had produced over 1500 physicians. However, it is unclear how many of these graduates were practising in Canada and, specifically, how many in NL. We conducted this study to determine the practice locations in 2004 of MUN medical graduates and to identify the characteristics and predictors of their working in Canada and in NL. We also report on our assessment of MUN's contribution to the physician workforce in NL and in Canada and suggest strategies to improve provincial and national retention. This article is based on a larger study that examined MUN's contribution to the national, provincial and rural physician workforce. Predictors of MUN medical graduates working in rural communities are reported elsewhere. ${ }^{5}$

\section{Methods}

The MUN Human Investigations Committee approved this study. We linked data obtained from Faculty of Medicine class lists, the alumni database and the postgraduate database with 
data obtained from the Southam Medical Database. Because data were not available in an electronic, linkable format, we linked data common to each data source (first and last and maiden names, sex, and year and school of graduation).

Our sample frame included all MUN medical students who graduated from 1973 (the first year medical students graduated from the university) to 1998 . We selected 1998 as the cutoff year to allow sufficient time for graduates to complete their residency training and enter practice. We excluded deceased and retired graduates because they were no longer part of the physician workforce. We excluded military physicians because they may have limited ability to choose their practice location, and we excluded Malaysian students who were sponsored by the Malaysian government and required to return home after completing their training.

We considered 2 outcomes: working in Canada in 2004, and working in NL in 2004. Work could be full or part-time, and in clinical, research or administrative positions. Physicians' locations were based on work addresses reported in the Southam Medical Database and, if unreported, in the MUN alumni database. The alumni database is updated annually, if necessary by contacting alumni's family. By using both of these databases, we were able to increase the number of cases with follow-up data from $65 \%$ to $98 \%$.

We examined the influence of 8 predictor variables on working in Canada and in NL: sex, residence background (rural v. urban), hometown location (Canada v. elsewhere, and NL v. elsewhere), year of graduation, location of residency training (some or all residency training at MUN v. elsewhere), specialty and age at graduation. On the basis of their hometown reported at the time of school admission, we determined whether graduates were from Canada, from NL and from a rural community (hometown population < I0 000). We grouped year of graduation into the 1970s (1973-1979), I980s (I980-I989) and I990s (I990-I998). Specialty was based on the physician's certified specialization as recorded in the Southam Medical Database or alumni database. We categorized each physician as either a family physician (general practitioner or family medicine specialist) or a specialist.

We used the $\chi^{2}$ test and analysis of variance to identify differences between each outcome and the predictor variables, and we used multiple logistic regression analysis to identify significant $(p<0.05)$ predictors for each outcome. Potential predictors for each regression model were selected on the basis of the bi-

\begin{tabular}{|c|c|c|c|c|c|c|}
\hline Characteristic & $\begin{array}{c}\text { Working } \\
\text { outside Canada } \\
n=175\end{array}$ & $\begin{array}{c}\text { Working } \\
\text { in Canada } \\
n=1147\end{array}$ & $p$ value & $\begin{array}{c}\text { Working } \\
\text { outside NL } \\
n=916\end{array}$ & $\begin{array}{l}\text { Working } \\
\text { in NL } \\
n=406\end{array}$ & $p$ value \\
\hline Sex, no. (\%) & $n=174$ & $n=1143$ & 0.005 & $n=911$ & $n=406$ & 0.78 \\
\hline Male & $119(68.4)$ & $652(57.0)$ & & $531(58.3)$ & $240(59.1)$ & \\
\hline Female & $55(31.6)$ & $491(43.0)$ & & $380(41.7)$ & $166(40.9)$ & \\
\hline Rural background, no. (\%) & $n=166$ & $n=1133$ & 0.06 & $n=893$ & $n=406$ & $<0.001$ \\
\hline No & $125(75.3)$ & $772(68.1)$ & & $644(72.1)$ & $253(62.3)$ & \\
\hline Yes & $41(24.7)$ & 361 (31.9) & & $249(27.9)$ & $153(37.7)$ & \\
\hline From Canada, no. (\%) & $n=174$ & $n=1147$ & $<0.001$ & $n=915$ & $n=406$ & 0.001 \\
\hline No & $10(5.7)$ & $13 \quad(1.1)$ & & $23 \quad(2.5)$ & 0 & \\
\hline Yes & $164(94.3)$ & $1134(98.9)$ & & $892(97.5)$ & $406(100)$ & \\
\hline From NL, no. (\%) & $n=174$ & $n=1147$ & 0.009 & $n=915$ & $n=406$ & $<0.001$ \\
\hline No & $58(33.3)$ & $277(24.1)$ & & $318(34.8)$ & $17 \quad(4.2)$ & \\
\hline Yes & $116(66.7)$ & 870 (75.9) & & $597(65.2)$ & $389(95.8)$ & \\
\hline Year of graduation, no. (\%) & $n=175$ & $n=1147$ & $<0.001$ & $n=916$ & $n=406$ & 0.73 \\
\hline 1973-1979 & $62(35.4)$ & $248(21.6)$ & & $211(23.0)$ & $99(24.4)$ & \\
\hline 1980-1989 & $66(37.7)$ & $459(40.0)$ & & $370(40.4)$ & $155(38.2)$ & \\
\hline 1990-1998 & $47(26.9)$ & $440(38.3)$ & & $335(36.6)$ & $152(37.4)$ & \\
\hline $\begin{array}{l}\text { Some or all residency training } \\
\text { at MUN, no. (\%) }\end{array}$ & $n=175$ & $n=1147$ & 0.005 & $n=916$ & $n=406$ & $<0.001$ \\
\hline No & $82(46.9)$ & 412 (35.9) & & $442(48.3)$ & $52(12.8)$ & \\
\hline Yes & $93(53.1)$ & $735(64.1)$ & & $474(51.7)$ & $354(87.2)$ & \\
\hline Specialty, no. (\%) & $n=175$ & $n=1147$ & 0.33 & $n=916$ & $n=406$ & 0.10 \\
\hline Specialist & $99(56.6)$ & $604(52.7)$ & & $501(54.7)$ & $202(49.8)$ & \\
\hline $\begin{array}{l}\text { Family physician or general } \\
\text { practitioner }\end{array}$ & $76(43.4)$ & $543(47.3)$ & & $415(45.3)$ & $204(50.2)$ & \\
\hline Age at graduation, mean (SD) & $26.5(3.8)$ & $26.6(3.3)$ & 0.99 & $26.6(3.3)$ & $26.4(3.4)$ & 0.49 \\
\hline
\end{tabular}

Note: $\mathrm{NL}=$ Newfoundland and Labrador, $\mathrm{SD}=$ standard deviation. 
variate analyses. Collinearity between predictor variables was examined a priori; large standard error values, indicative of multicollinearity, were not found in the regression models.

\section{Results}

Of the 138I physicians who graduated from MUN between I 973 and 1998, 59 were excluded (20 deceased, 7 retired, Io military physicians, 5 graduates sponsored by the Malaysian government, and I7 location unknown). This left 1322 graduates for our study.

The majority of the medical graduates in our study were male (58.5\% [771/1317]), had an urban background (69.1\% [897/I299]), were from Canada (98.3\% [1298/132I]) and NL (74.6\% [986/132I]), did at least some of their postgraduate residency training at MUN $(62.6 \%[828 / \mathrm{I} 322])$ and were specialists $(53.2 \%[703 / 1322])$. The mean age at graduation was 26.5 years. The majority $(86.8 \%$ [II47/I322]) were working in Canada in 2004. Almost one third of the graduates $330.7 \%$ [406/1322]) were working in NL in 2004.

Compared with those working outside Canada, a significantly larger proportion of graduates working in Canada were female, from Canada, from NL, had graduated in the I98os or I9gos and had completed at least some of their postgraduate residency training at MUN (Table I). There was no difference between these 2 groups in terms rural or urban background, specialty or age at graduation. After controlling for other significant predictors in the logistic regression analysis, we found that female sex, being from Canada, graduating in the I980s and I9gos and completing some or all residency training at MUN were significant predictors for working in Canada in 2004 (Table 2).

Compared with the graduates working outside NL, a significantly larger proportion of those working in the province had a rural background, were from Canada, were from NL and completed some or all of their residency training at MUN (Table I). There were no differences between these physicians groups with regard to sex, year of graduation, specialty or age at graduation. After controlling for other significant predictors, we found that having a rural background, being from $\mathrm{NL}$ and completing at least some residency training at MUN were significant predictors of working in NL (Table 2). Of the 986 graduates from NL, $389(39.5 \%)$ were working in the province in 2004, and I49 (45.8\%) of the 325 graduates from rural NL were working in the province in 2004. Over half (I3I [55.5\%]) of the 236 graduates from rural NL who had also done some or all of their residency training at MUN were working in the province in 2004.

\section{Interpretation}

In 2004, $86.8 \%$ of the MUN graduates in our study were working in Canada, and $30.7 \%$ were working in NL. The national retention rate is similar to the $88.5 \%$ reported by Ryten and colleagues, ${ }^{4}$ although they included physicians in practice and those in training, which could produce a higher rate. MUN graduates accounted for $52.6 \%$ of the fully licensed physicians in the province (unpublished observations), which suggests that the MUN medical school has contributed substantially to the local physician supply and eased dependence on other Canadian and international medical schools. Participating in postgraduate residency training at MUN was a significant predictor of working in Canada and in NL. Providing incentives for local medical graduates to complete their postgraduate training in their home province may increase provincial retention. Similarly, a previous Canadian study reported that a strong predictor of emigration to the United States was completing postgraduate training in the United States. However, McKendry and associates $^{6}$ suggested that, rather than a US-based residency influencing physicians to emigrate, physicians consider moving to the United States much earlier in their training and purposefully choose a US-based residency. There is a need, therefore, to identify at the time of admission the traits of trainees who are more likely to remain in Canada or the province.

We found that the MUN graduates from Canada were more likely than the MUN graduates from other countries to remain in Canada and NL and that the graduates with rural backgrounds were more likely than those with urban backgrounds to remain in NL. These findings support policies in Canadian

Table 2: Factors predicting whether medical graduates of Memorial University of Newfoundland (MUN) were working in Canada and in Newfoundland and Labrador (NL) in 2004

\begin{tabular}{lcc}
\hline & $\begin{array}{c}\text { Crude OR } \\
\text { Factor }\end{array}$ & $\begin{array}{c}\text { Adjusted OR } \\
(95 \% \mathrm{Cl})\end{array}$ \\
\hline
\end{tabular}

\begin{tabular}{|c|c|c|}
\hline Working in C & & \\
\hline Sex & & \\
\hline Male & $1.00^{*}$ & $1.00^{*}$ \\
\hline Female & $1.63(1.16-2.29)$ & $1.44(1.01-2.04)$ \\
\hline From Canada & & \\
\hline No & $1.00^{*}$ & $1.00^{*}$ \\
\hline Yes & $5.32(2.30-12.33)$ & $3.71(1.15-2.21)$ \\
\hline Year of gradu & & \\
\hline 1973-1979 & $1.00^{*}$ & $1.00^{*}$ \\
\hline 1980-1989 & $1.74(1.19-2.54)$ & $1.52(1.02-2.24)$ \\
\hline 1990-1998 & $2.34(1.55-3.53)$ & $2.01(1.31-3.09)$ \\
\hline $\begin{array}{l}\text { Some or all } \\
\text { training at } M L\end{array}$ & & \\
\hline No & $1.00^{*}$ & $1.00^{*}$ \\
\hline Yes & $1.57(1.14-2.17)$ & $1.59(1.53-9.01)$ \\
\hline Working in $\mathrm{N}$ & & \\
\hline Rural backgro & & \\
\hline No & $1.00^{*}$ & $1.00^{*}$ \\
\hline Yes & $1.56(1.22-2.01)$ & $1.37(1.04-1.81)$ \\
\hline From NL & & \\
\hline No & $1.00^{*}$ & $1.00^{*}$ \\
\hline Yes & $12.19(7.36-20.18)$ & $9.23(5.52-15.44)$ \\
\hline $\begin{array}{l}\text { Some or all } r \\
\text { training at } M L\end{array}$ & & \\
\hline No & $1.00^{*}$ & $1.00^{*}$ \\
\hline Yes & $6.35(4.62-8.73)$ & $5.28(3.80-7.34)$ \\
\hline
\end{tabular}

Note: $\mathrm{OR}=$ odds ratio, $\mathrm{Cl}=$ confidence interval.

${ }^{*}$ Reference category. 
medical schools that give priority for admission to students from that province as well as initiatives that encourage rural students to pursue medical careers. Currently, 40 of $60 \mathrm{MUN}$ seats are reserved for students from NL, Io for students from New Brunswick and 2 for students from Prince Edward Island. Of note, $30.9 \%$ of all MUN graduates had a rural background, compared with only 10.8\% of Canadian medical students. ${ }^{7}$ Of the MUN graduates who were from NL, 33.0\% had rural backgrounds and were more likely than urban NL graduates to be working in NL in 2004. Policies that give higher priority for admission to rural students may also increase the number of rural physicians, since rural background is a strong predictor of rural practice..$^{8-13}$ The predictors of MUN medical graduates working in rural NL and Canadian communities are reported elsewhere. ${ }^{5}$

Contrary to findings from other studies, ${ }^{6}$ our study showed that recent graduates (Classes of I990-I998) were less likely than their more senior counterparts to emigrate from Canada. This may be related to generational differences; it has been suggested that more recent graduates place greater value on a "balanced lifestyle"14,15 and may choose positions in Canada that allow them to limit their practice commitments. The differences may also stem from US immigration policies and recruitment strategies that drew physicians in the rg9os.

As in other studies, ${ }^{6}$ we found that female physicians were more likely than male physicians to remain in Canada. However, provincial retention of graduates was not related to sex, which suggests that the province is equally effective at retaining male and female medical graduates. Further research is needed to understand and monitor the impact of the increasing number of women in the physician workforce, which this study suggests may increase national physician retention.

We were unable to find other Canadian studies that have examined factors related to the provincial retention of local medical school graduates. Further studies are needed to clarify which factors are universal and which are specific to the medical school or the province, since recruitment and retention of physicians is a complex process combining both education and non-education factors.

Our study had limitations. Using a cross-sectional design, we were able to identify only the 2004 practice location of the graduates. Although physicians may have practised for much of their careers elsewhere and only recently returned to NL, the converse is more likely, that is, many MUN graduates may have practised in NL for some or many years and then relocated to other Canadian provinces. Moreover, the use of secondary administrative data limits the number and type of variables examined. Primary data are needed to examine a greater range of variables.

\section{Conclusion}

Between 1973 and 1998 the MUN medical school trained 138 I physicians. Of the 1322 graduates included in our study, $86.8 \%$ were working in Canada and $30.7 \%$ in NL in 2004. Over half (55.5\% [I3I]) of the 236 graduates from rural NL who had also done some or all of their residency training at MUN were working in NL in 2004. The MUN medical school has made a substantial contribution to the local physician supply, producing over half the physicians working in the province in 2004. Initia- tives to increase the national and provincial retention of medical graduates include attracting rural students to medical careers, increasing admission of local students and providing incentives for graduates to complete their residency training in the province where they graduated.

\section{This article has been peer reviewed.}

From the Division of Community Health \& Humanities (Mathews, Park) and the Dean's Office (Rourke), Faculty of Medicine, Memorial University of Newfoundland, St. John's, NL

Competing interests: None declared.

Contributors: Maria Mathews designed the study, analyzed and interpreted the data, and drafted and revised the manuscript. Jim Rourke contributed to the study design, data interpretation and revisions of the manuscript. Amanda Park constructed the database and contributed to the data interpretation and revisions of the manuscript. All of the authors approved the final draft of the manuscript.

Acknowledgements: Maria Mathews holds a New Investigator's Award from the Canadian Institutes of Health Research (Regional Partnership Program). Amanda Park holds a masters fellowship from the Atlantic Regional Training Centre funded by the Canadian Health Services Research Foundation/Canadian Institutes of Health Research.

\section{REFERENCES}

I. Barer ML, Webber WA. The great Canadian physician exodus? Isuma Can J Policy Res 2000;I(2):94-IOI.

2. Physicians moving abroad and returning from abroad, by province/territory, Canada 2000-2004 [table]. Ottawa: Canadian Institute for Health Information. Available: www.cihi.ca/cihiweb/en/ARI4_2002_tab7_e.html (accessed 2006 June 29).

3. Supply, distribution and migration of Canadian physicians 2004. Ottawa: Canadian Institute for Health Information; 2005. Available: http://secure.cihi.ca/cihiweb /products/SupDistandMigCanPhysic_2004_e.pdf (accessed 2006 Jun 29).

4. Ryten $\mathrm{E}$, Thurber $\mathrm{AD}$, Buske L. The Class of $\mathrm{I} 989$ and physicians supply in Canada. CMAJ I998;158(6):723-8.

5. Social accountability - a vision for Canadian medical schools. Ottawa: Health Canada; 200I. Available: www.bcahc.ca/pdf/Social\%20Accountability\%20-\%20 A\%20Vision\%2ofor\%20Canadian\%20Medical\%20Schools.pdf (accessed 2006 Jun 29). Cat no $\mathrm{H}_{39}-602 / 2002$.

6. McKendry RJ, Wells GA, Dale P, et al. Factors influencing the emigration of physicians from Canada to the United States. CMAJ I996;I54(2):I7I-8I.

7. Dhalla IA, Kwong JC, Streiner DL, et al. Characteristics of first-year students in Canadian medical schools. CMAJ 2002;166(8):1029-35.

8. Bible BL. Physicians' views of medical practice in nonmetropolitan communities. Public Health Rep I970;85:II-7.

9. Brooks RG, Walsh M, Mardon RE, et al. The roles of nature and nurture in the recruitment and retention of primary care physicians in rural areas: a review of the literature. Acad Med 2002;77:790-8

Io. Easterbrook M, Godwin M, Wilson R, et al. Rural background and clinical rural rotations during medical training: effect on practice location. $C M A J$ I999;I6o(8):II59-63

II. Johnson SE, Baeumler WL, Carter RE. The family physicians: a comparative study of Minnesota and Wisconsin family physicians practicing in rural and urban communities. Minn Med 1973;56:713-8.

I2. Rourke JTB, Incitti F, Rourke LL, et al. Relationship between practice location of Ontario family physicians and their rural background or amount of rural medical education experience. Can J Rural Med 2005;I0:23I-9.

I3. Rourke J; Task Force of the Society of Rural Physicians of Canada. Strategies to increase the enrolment of students of rural origin in medical school: recommendation from the Society of Rural Physicians of Canada. CMAJ 2005;172(I):62-5.

I4. Moody J. Recruiting Generation X physicians. Recruiting Physicians Today [newsl] 2002;Jan-Feb. Available: www.nejmjobs.org/rpt/recruiting-gen-x-physicians.aspx (accessed 2006 Jun 30).

I5. Watson DE, Katz A, Reid RJ, et al. Family physician workloads and access to care in Winnipeg: I991 to 200I. CMAJ 2004;171(4):339-42.

Correspondence to: Dr. Maria Mathews, Division of Community Health and Humanities, Memorial University of Newfoundland, Health Science Centre, St. John's NL AIB 3V6; fax 709 777-7382; mmathews@mun.ca 